Management options

\title{
The management of central post-stroke pain
}

\author{
David Bowsher
}

\section{Summary}

Central post-stroke pain (CPSP) used to be known as 'thalamic syndrome'. Early post-mortem studies showed that many cases had extrathalamic lesions, and modern imaging methods have confirmed and extended these findings.

CPSP affects between 2 and $6 \%$ of stroke patients, ie, there is an annual incidence in the UK of between 2000 and 6000 . Most patients with CPSP appear to be younger than the general stroke population, and usually to have relatively mild motor affliction; thus they may live for many years, giving a prevalence perhaps as high as 20000 .

True CPSP, characterised by a partial or total deficit for thermal and/or sharpness sensations, is best treated initially with adrenergically active antidepressants. If these do not work, mexiletine may be added in suitable cases. Recent studies suggest that stimulation of the motor cortex or spinal cord by implanted electrodes may help patients resistant to medical treatment. Positive relaxation, as an adjuvant therapy, should be used in nearly all cases.

Considerable or even total relief can be achieved in almost two thirds of patients. There is evidence that the sooner antidepressant treatment is begun, the more likely the patient is to respond; time should not be wasted trying conventional analgesics, which rarely have any significant effect.

Keywords: pain management, stroke, antidepressants

Pain Research Institute, Walton Hospital,

Liverpool L9 1AE, UK

D Bowsher

Accepted 19 April 1995

Central post-stroke pain (CPSP) was first described as 'thalamic syndrome' by Dejerine and Roussy in $1906 .{ }^{1}$ Cases due to cortical lesions were described by Foix et al in 1927, ${ }^{2}$ and called 'pseudo-thalamic syndrome', and Ajuriaguerra ${ }^{3}$ described a large number of cases due to bulbar infarction (Wallenberg's syndrome). Cassinari and Pagni ${ }^{4}$ suggested that the syndrome could occur following lesions anywhere along the course of the classical spinothalamic pathway (figure 1) and its corticopetal projections. Computed tomography (CT), and later magnetic resonance imaging (MRI) revealed that many, if not most, cases had extrathalamic lesions (figure 2 ).$^{5-9}$ For these very adequate reasons, the term 'thalamic syndrome' is no longer used, and has been replaced by CPSP. MRI scans are now beginning to reveal patients with lesions in areas such as the ventroposterolateral thalamus who have not got CPSP.

Even CPSP may be a bit of a misnomer. Davison and Schick ${ }^{10}$ had already demonstrated anatomo-pathologically a number of cases in which the lesion was not an infarct following a classical stroke. We found that 20 to $25 \%$ of our cases followed subarchnoid haemorrhage, including patients treated conservatively. ${ }^{11}$ Davison and Schick ${ }^{10}$ reported at least one case with a (thalamic) tumour, and many cases have now been described which do not follow infarct. However, in clinical practice the vast majority of cases follow stroke or subarchnoid haemorrhage.

Starting with Dejerine and Roussy in $1906,{ }^{1}$ and reiterated by Garcin, ${ }^{12}$ many authors have remarked upon the lack of response of central pain to (conventional) analgesics. In the days of 'slash and burn' neurosurgery, this led to attempts to relieve the pain by cutting the 'pain pathways' (ie, anterolateral cordotomy) in cases where the pain was expressed mainly or even entirely in a body region below a surgically accessible spinal level. Not only did this procedure not work, but many of its proponents apparently failed to notice the close pathophysiological similarity between 'thalamic syndrome' and spontaneously painful postcordotomy dysaesthesia. In this context, it is interesting to note that Garcin $^{12}$ had remarked on the impossibility of distinguishing the types of pain and sensory change in syringomyelia from those in 'thalamic syndrome', an observation that we have been able to repeat using quantitative methods. Even bolder neurosurgeons later proceded to make lesions in the brain, including enlargement of pre-existing thalamic infarcts. Such lesions frequently gave up to three months relief, just as iatrogenically produced holes anywhere in the

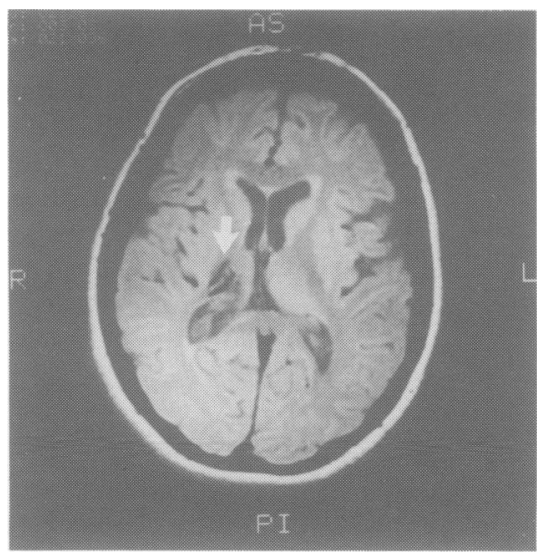

Figure 1 MRI of a lacunar lesion (arrow) in the right thalamus, causing CPSP affecting the left lower limb

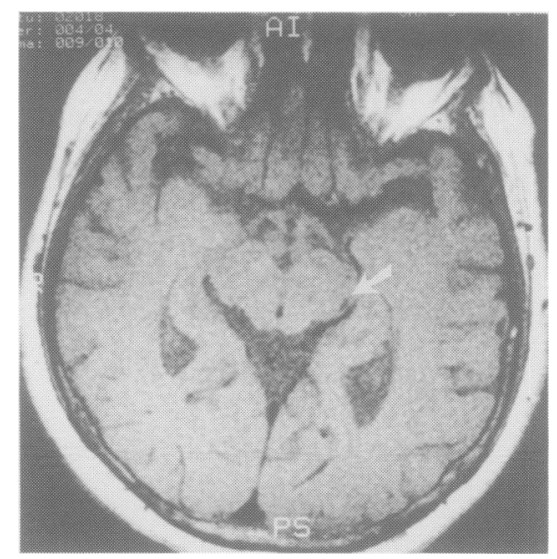

Figure 2 MRI of a very small lesion (arrow) in the midbrain spinothalamic tract, causing CPSP affecting the contralateral arm and leg 


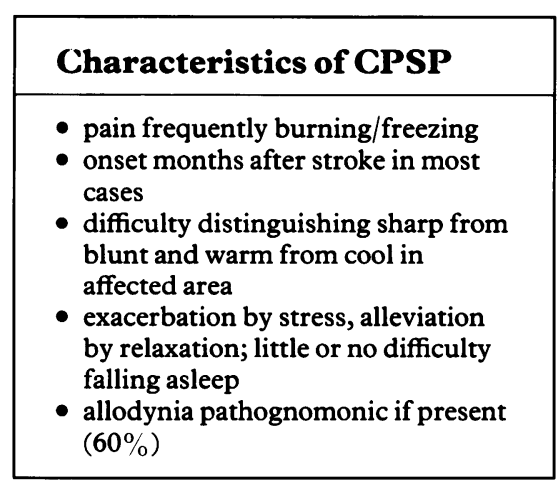

Box 1 forebrain had been shown to give short-duration symptomatic relief of Parkinson's disease. However, the idea of enlarging pre-existing thalamic lesions was not as stupid as it may sound, since there are a number of reported cases of CPSP being 'cured' by subsequent strokes.

\section{Neurogenic pain}

CPSP, like all other pains, was originally treated with conventional analgesics, although it had been recognised that very little effect was obtained, except perhaps in some cases by near-anaesthetic doses of opioid. It was the recognition that there are two categories of pain which led to a more hopeful outlook in CPSP and similar conditions.

Most pain is caused by the stimulation of nociceptors, ie, specific tissuedamage receptors connected to (small) nerve fibres in skin and other tissues. Centrally, the nociceptor-activated peripheral nerve fibres are connected, via opioid-sensitive synapses, to the central 'pain pathway' which ascends in the anterolateral funiculus of the spinal cord to relay in the brainstem reticular formation and intralaminar thalamus ${ }^{13}$ and whose impulses are eventually distributed to the whole cerebral cortex, with prefrontal and anterior cingulate predominance ${ }^{14}$; a component (the classical 'spinothalamic' pathway) runs clear through the brainstem to the ventroposterior thalamus whence it is relayed to the primary and secondary somatosensory cortices (postcentral gyrus and retroinsular region). This latter projection is responsible for thermal and pinprick sensation, as well as the localisation of painful and other somatosensory stimuli ( $\mathrm{se}^{15}$ for a recent review). This category of tissue-damage pain is now known as nociceptive pain. Nociceptive pain in the form of frozen shoulder is common in strokes both without and with central pain, and so may co-exist with CPSP.

A quite separate category of neurogenic pain is now recognised. In this, there is no stimulation of peripheral nociceptors (as demonstrated par excellence by CPSP, where pain is caused by a brain lesion), but there is dysfunction of the nervous system causing pain. Other features of neurogenic pain include the following:

- The word most frequently used by patients to describe neurogenic pain is burning. More articulate patients may (more pathognomonically) describe ice-burn (paradoxical burning). Stabbing/shooting pain may also lead to suspicion of neurogenic origin.

- There is autonomic instability, often evidenced subjectively by exacerbation on physical (cold environmental) or emotional stress and alleviation by relaxation. These patients are notoriously able to fall asleep without difficulty, though they may be woken by pain (?REM sleep) or have difficulty remaining asleep. Thus the common question 'How do you sleep?' needs to be carefully modified. Objectively, autonomic instability is frequently evidenced by cutaneous vasoconstriction (or occasionally dilation); the affected limbs of CPSP patients are frequently cold, and they may volunteer that when the pain is bad, cold is felt particularly intensely. Another objective sign of autonomic instability of not infrequent occurrence is hyper- (rarely hypo-) hidrosis in all or part of the affected area.

- In addition to any deficit for large-fibre sensations such as touch with cotton wool, which occurs in up to $25 \%$ of pain-free stroke patients ${ }^{16}, 99 \%$ of CPSP patients have a deficit for pinprick and/or thermal sensation. Pinprick sensation, of course, means the ability to distinguish between the point and the head of pain - sharp/blunt discrimination - not the ability to feel a pin driven in to the hilt and stirred around as 'painful'. Similarly, and perhaps even more importantly, subtotal thermal deficit is best tested, first by asking the patient (if an extremity is involved) whether they can tell whether a basin/bath is too hot or too cold if they put the affected hand/foot in first, and then by asking them to distinguish, with eyes closed, which is warmer or colder - the examiner's finger or an unwarmed tuning fork (or metal spoon handle). There is no need to mess about with test tubes containing hot and cold water, because one is not attempting to test for total loss of extremes of temperature sensation. Because a partial deficit is what usually exists, pain sensation following the application of a hot stimulus $\left(>45^{\circ} \mathrm{C}\right)$ is frequently unaffected, as is mechanical painful sensation on skinfold pinch (though the threshold for this is greatly raised in spinal lesions producing spontaneous neurogenic pain). The area of sensory change in CPSP is nearly always considerably more extensive than the area which is painful.

- Allodynia - the elicitation of pain by a non-painful stimulus - when it occurs, is pathognomonic of neurogenic pain. About $60 \%$ of patients with CPSP have allodynia. The most frequent form is tactile, produced by a light, moving, 
stimulus, but not by a sustained mechanical stimulus (= pressure), which may even relieve pain. This latter phenomenon clearly distinguishes allodynia from tenderness produced by (nociceptive) inflammation. Cold, and very occasionally warm, allodynia may also occur. Patients with CPSP may also report pain on movement; some indeed have no pain if they keep absolutely still. Examination reveals that this pain is produced by both isotonic and isometric muscle contraction, and is therefore presumably attributable to stretch receptors in muscle and/or tendon. It represents movement allodynia. Some patients may have more than one form of allodynia. Conversely to what obtains for sensory change, the region from which allodynia is obtained is usually (but not always) only part of the whole area affected by pain.

\section{Diagnosis of CPSP}

The characteristics of the central pain experienced by CPSP patients have been described above. What sort of patients get CPSP?

A little under half of CPSP patients experience pain starting at the same time as the stroke. More than half of them first experience pain from days to months afterwards; the median time is three months, and in $95 \%$ of these patients, pain begins between three and nine months after stroke. This has an important implication, because it means that the majority of these patients will have returned to primary care before central pain becomes apparent.

While profound -plegia or -paresis can occur in CPSP, the motor affliction in CPSP is often relatively mild. In $>100$ personal cases, noteworthy plegia or paresis was found in only $8 \%$ at the time of presentation with CPSP. Many more patients, of course, had had a more severe initial motor deficit; and a very significant number reported that their pain came on pari passu with motor recovery.

There is a tendency for CPSP patients to be younger than most stroke patients. The median age at stroke of our own group was 59 years, whereas the median age at ictus in the whole stroke population is over 70 years. The median age of our SAH patients who developed CPSP was 45 years.

Fewer than half our patients had pain involving half the body (including or excluding the face and head), while in the rest smaller areas (sometimes very small areas) were concerned. There may be painless sensory change in part of the body and painful change in another; this is particularly noticeable in patients with crossed (lower brainstem) strokes (10\% of our series). Furthermore, within the painful area, there are regions of greater and lesser pain intensity. Overall pain intensity frequently fluctuates in an apparently random manner.

Since response to treatment in CPSP seems to depend to a considerable extent on its early initiation (see below), it is important that doctors concerned with stroke patients in hospital warn their colleagues in primary care what to look out for. The simplest and perhaps most reliable test which should be carried out by the general practitioner is: in any stroke patient complaining of pain, test the ability to distinguish sharp from blunt and warm (examiner's finger) from cool (cold metal) in the painful area; if either or both of these are abnormal, then CPSP is almost certainly present. Allodynia to a light, moving, stimulus or cold is pathognomonic, but its absence does not exclude.

\section{Management of CPSP}

ASSESSMENT

Let it first be said that nociceptive pain such as frozen shoulder should be dealt with appropriately (ie, by intracapsular injection followed by physiotherapy) in CPSP patients. Secondly, these patients may require the usual rehabilitative measures applicable to any stroke patients, although features such as allodynia may make such management difficult or even impossible.

The progress of CPSP, like any other pain, cannot be assessed by writing comments such as 'better', 'worse', or 'unchanged' in the case-notes. Better than what? No physician would dream of writing 'pulse-rate increased' without giving a number to it, and the same goes for pain. By far the best measure of pain intensity is the Visual Analogue Scale (VAS) ${ }^{17}$ It consists of a line $100 \mathrm{~mm}$ long, at one end of which is written 'No pain' and at the other 'Worst pain ever experienced'. The patient is asked to make a mark on the line at a point corresponding to the intensity of his/her pain at that moment (figure 3 ). ${ }^{\star}$ Intensity is then recorded as the number of millimetres between 0 and 100 . While different subjects cannot be compared with each other, the VAS provides an extremely accurate measure of an individual patient's progress.

There are, however, some provisos to be made in the assessment of CPSP and other neurogenic pains. Pain intensity may fluctuate, and amelioration may 


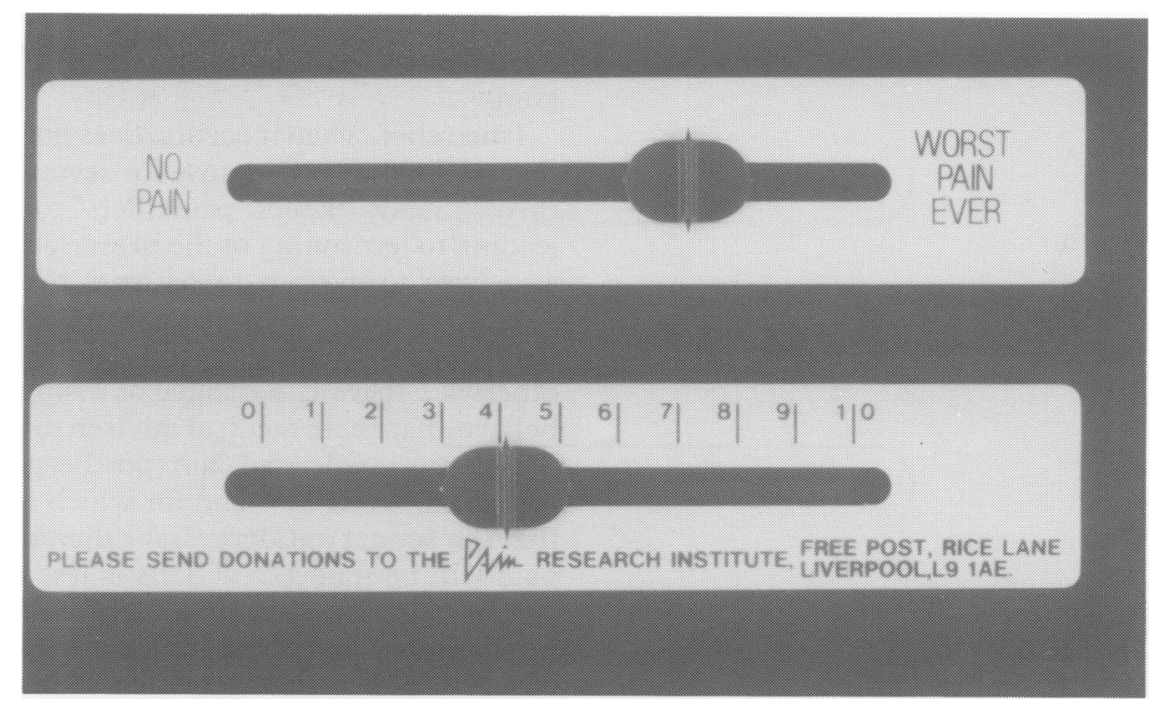

Figure 3 Visual Analogue Scale. The patient can put the red slider anywhere between 'No pain' and 'Worst pain ever'; the centimetre scale is on the back, and is only seen by the person administering the test.

consist of longer periods of less intense pain interspersed with shorter periods of more intense pain. In CPSP, improvement may also be shown by a shrinkage of the area in which pain is felt. Lastly, there may be a dissociation between allodynia and background pain.

Treatment of CPSP
- start adrenergically active
antidepressant (amitriptyline,
nortriptyline, desipramine,
maprotiline) as soon as possible
after pain onset
- do not waste valuable time trying
conventional analgesics first
- if insufficient relief from tolerated
antidepressant, consider adding
mexiletine
- if antidepressant or antidepressant
+ mexiletine do not work, refer to a
pain clinic

Box 2

\section{DRUG TREATMENT}

It has already been stated that the ineffectiveness of conventional analgesics, including opioids, has been noted since the syndrome was first recognised. This has, unfortunately, not prevented a very large number of practitioners from administering ever-stronger analgesics to these unfortunate patients. The present author has had to detoxify a number of agonised geriatric junkies, high on slow-release morphine, before appropriate treatment could be started.

Destructive neurosurgery may also be excluded in the present era, and we should pass straight to the modern age. The realisation that neurogenic pain was in a different pathophysiological category has come only gradually. ${ }^{18} \mathrm{Car}-$ bamazepine has continued to be used right up to the present time, although a carefully controlled trial has shown it not to be effective in a statistically significant manner in CPSP. ${ }^{19} \mathrm{~A}$ double-blind cross-over trial ${ }^{20}$ failed to find any therapeutic effect of naloxone in relieving CPSP and this treatment has fallen into disuse. Regional sympathetic blockade has also been advocated in CPSP but none of our patients to whom it was administered received any long-term benefit.

\section{Antidepressants}

Antidepressants have been in use for some time in the treatment neurogenic pains, including central syndromes. ${ }^{22}$ However, the scientific basis for this was not established until the publication of Leijon and Boivie, ${ }^{19}$ which showed a positive response to amitriptyline in 10 out of 15 CPSP patients in a double-blind cross-over trial. They stated that the effect appeared to be correlated with the plasma levels of the drugs, a level of $>300 \mathrm{nmol} / 1$ being associated with a positive effect. Unfortunately there is little correlation between oral dose and plasma level, which may explain the failure of some patients to respond. ${ }^{23} \mathrm{~A}$ number of human and animal studies have shown adrenergically active antidepressants to be effective, and purely serotonergically active antidepressants to be ineffective, in neurogenic pain. ${ }^{24-27}$ Our own clinical experience has shown that antidepressants without a strong adrenergic activity are not generally helpful in the treatment of neurogenic pain.

The response to different antidepressants is highly idiosyncratic, but the usual order in which effective drugs are tried is: amitriptyline, nortriptyline, desipramine, maprotiline. All have a long biological half-life, and the whole daily dose can be taken at bedtime in order to avoid diurnal side-effects and promote sleep; some patients, however, find they need to take the drugs in divided doses. It is usual to start with 10 or $25 \mathrm{mg}$, and to increase weekly by 10 or $25 \mathrm{mg}$ until 50 or preferably $75 \mathrm{mg}$ are being taken daily (if tolerated). In our experience, it is rarely beneficial to go above $75 \mathrm{mg}$, except in those patients who obtain some, but inadequate, relief from $75 \mathrm{mg}$ daily. All these drugs cause dry mouth, which is the 
commonest cause of non-compliance with these antidepressants. This can be overcome by the co-prescription of artificial saliva spray, or by the use of chewing gum.

Pain relief, when it occurs, does not usually begin until the patient has been on the maximal tolerated dose for several weeks. Patients need to be warned about this, as many expect 'painkillers' to have an immediate effect, or none at all, leading to jettisoning of the prescription after the first dose by the unready. It is also wise to explain to patients that first-generation antidepressants have a specific effect on neurogenic pain unrelated to their mood-elevating action ${ }^{28}$ and that they are being prescribed for this and not for their antidepressant effect; otherwise there is a danger of losing the confidence of patients who come to believe that their medical adviser thinks their pain is 'psychological'.

In zoster-associated pain (postherpetic neuralgia), which has similar signs and symptoms to $\operatorname{CPSP}^{29}$ and for which similar treatment is used, it is very evident that the sooner antidepressant therapy is initiated, the more likely it is that the pain will be relieved ${ }^{18,30}$ This is less clear in the case of CPSP because, unlike zoster, pain does not immediately follow upon the ictus in the majority of cases. Furthermore, it has unhappily been rare in the past for antidepressant treatment of CPSP patients to be started soon after pain onset. In the author's personal series of CPSP patients, 31 pain-relieved subjects began antidepressants at a median of 18 months after pain onset, while 26 unrelieved patients did not start antidepressants until a median of 29 months after pain began; this difference is significant at the $5 \%$ level. Another way of looking at our series is to state that $35 \%$ of relieved patients began their antidepressant treatment less than a year after pain onset, while only $19 \%$ of relieved patients began their antidepressant treatment more than a year after pain onset. There seems therefore to be a strong case for initiating antidepressant treatment as early as possible after a diagnosis of CPSP has been made. This in itself is a powerful argument for not beginning by seeing what conventional analgesics will do (for those of an enquiring turn of mind, the answer is nothing, or at best very little).

Apart from the early initiation of antidepressant therapy, are there any other factors which influence pain relief? In the present authors' experience, patients complaining of typically neurogenic pain (burning, freezing, stabbing/shooting, hot pins and needles) tend to respond better than subjects afflicted by aching or throbbing 'dull' pain, in the ratio 8:5. Patients without allodynia have tended to respond better than those with it, and those with late pain onset better than those with immediate onset. It must, however, be stressed that these are only tendencies: plenty of allodynic patients with immediate onset of aching pain have obtained pain relief.

\section{Anticonvulsants}

Anticonvulsants should certainly never be used as monotherapy for CPSP; the data on carbamazepine by Leijon and Boivie ${ }^{19}$ have been referred to above. Combined therapy with antidepressants is, however, acceptable, and has been used by many $a b$ initio, including the present author in earlier years. The usual drug of first choice has been sodium valproate $(200 \mathrm{mg}$ tid), followed by carbamazepine, followed by phenytoin. It is now my practice always to begin with antidepressant monotherapy, and only to add other drugs if response is incomplete or lacking. On this basis, it is fairly rare, but not unknown, that the addition of anticonvulsants to antidepressants can be helpful. One remarkable success was obtained with vigabatrin, which has not been helpful in other patients in whom it has been tried. As a GABA agonist, there is a rationale for using it to overcome tactile allodynia, which is conveyed by $\beta$ primary afferents, ${ }^{31}$ whose intraspinal collaterals are inhibited by GABA-ergic islet cells in the substantia gelatinosa. ${ }^{32}$

\section{Anti-arrhythmics}

Mexiletine was recommended by Awerbuch and Sandyk ${ }^{33}$ for the treatment of CPSP. It has been given to more than 25 of my patients who have failed to respond to antidepressant monotherapy, using the protocol described in box 3 . This regime (antidepressant + mexiletine) can have a dramatic effect, with pain relief occurring within a few days. Mexiletine without antidepressant seems, in our experience, to be less effective. Some physicians give mexiletine on an out-patient basis, starting with a low dose and building up. The results of this have not been fully evaluated, but are certainly less dramatic and probably less effective.

\section{Calcium channel blockers}

Low-dose calcium channel blockers (eg, nifedipine) will bring about selective cutaneous vasodilation and a feeling of warmth in areas where the stroke has 

some patients are glad to get rid of a distressing feeling of coldness which may affect a whole limb.

\section{Other drugs}

Many other drugs have been tried in CPSP, but none have consistently been shown to be effective. In theory, NMDA receptor antagonists such as ketamine or even dextromethorphan could relieve neurogenic pain, and clinical trials are eagerly awaited.

\section{STIMULATION (SURGICAL TREATMENT)}

Implanted stimulators may also have a place in the treatment of CPSP. Naturally, surgery is not attempted until all forms of medical treatment have been found to fail, so no great claims can be made for universal success in these recalcitrant cases. Spinal cord stimulation by implanted epidural electrodes has been used in cases where pain is felt in one limb only; it is most successful when the patient has no deficit for low-intensity mechanical stimuli, and of course it is essential that paraesthesiae be felt in the painful area on stimulation (JB Miles, personal communication). The most exciting development of recent years has been the successful application of subthreshold stimulation of the motor cortex by Tsubokawa and colleagues. ${ }^{34}$ Again, stimulation must be carried out in that part of the motor cortex which controls motor function in the affected area. The fact that the effective intensity of stimulation does not elicit muscle contraction must mean that cortical interneurones are being activated. It is known that some low-intensity mechanical sensations can be suppressed from motor cortex,,$^{35,36}$ and it seems reasonable to assume that pain may also be susceptible.

\section{Prognosis}

How long should successful drug treatment for CPSP be continued? There is no golden rule. If pain is abolished or very greatly reduced, nothing should be altered for at least six months after this happy event has occurred. After that, dosage may be cautiously reduced by steps, eg, if amitriptyline was being taken at a daily dose of $75 \mathrm{mg}$, reduce to $50 \mathrm{mg}$. Each step down should be maintained for a month or even six weeks; if pain recurs, the former dose must be immediately restored. If pain remains absent, or sufficiently reduced, further progressive reductions may be undertaken. Even if it becomes possible to stop antidepressants altogether, the patient should keep a supply handy, and be instructed to recommence immediately, in progressive fashion, should pain recur at any time. Far too many patients stop taking drugs as soon as the pain has disappeared and do not re-start until told to do so by a neurologist or pain specialist, which is often several months later. By this time the pain has sadly become unresponsive to the antidepressant originally used, and frequently to all the others too. Patients must be warned about the dangers of stopping treatment too soon, and of the importance of immediate treatment for any recurrence. Many patients need to stay on appropriate medication for life.

In our practice, about half of the patients referred have obtained pain relief ( $>50 \%$ fall on VAS) from treatment with antidepressant alone or antidepressant + anticonvulsant (earlier cases); a further $20 \%$ have obtained relief from the addition of mexiletine to antidepressant. Of the remainder, although classed as 'treatment failures', a number have recorded a consistent $20 \%$ fall on VAS, which is better than nothing. If anything in the therapeutic world is certain, it is that if antidepressant treatment were started earlier, a higher proportion of patients would have their pain relieved. It would therefore be useful if research were to be undertaken to find out whether there are any factors which might predict which stroke patients are likely to develop CPSP. A combination of early drug treatment, possibly including new types of drugs, and neurosurgically implanted stimulators may well go far to rid us of a distressing condition which may persist for many years and probably affects up to 20000 people in the UK.

\section{Box 4}

1 Dejerine J, Roussy J. Le syndrome thalamique. Rev Neurol 1906; 14: 521-32

2 Foix Ch, Chavany J-A, Lévy M. Syndrome pseudo-thalamique d'origine pariétale. Lésion de l'artère du sillon interpariétal. CR Soc Neuro (Paris) 1927; 168-75.

3 Ajuriaguerra J de. La douleur dans les affection du systéme nerveux central. Doin, Paris, 1937.

4 Cassinari V, Pagni CA Central pain A neurosurgical survey. Cambridge, MA: Harvard UP, 1969.

5 Agnew DC, Shetter AG, Segall HD, Flom RA.

Thalamic pain. Adv Pain Res Ther 1983; 5 : $941-6$.
6 Bowsher D, Lahuerta J, Brock LG. Twelve cases of central pain, only three with thalamic lesions. Pain 1984; suppl 2: 83 .

7 Bowsher D, Lahuerta J, Brock LG. A note on the relationship between site of interruption and somatosensory thresholds in lesions of hum pain pasury In: Shold in lesions of human pain pathway. In: Schmidt RF et al, eds. Fine Gesellschaft, 1987; and pain.,

8 Bowsher D, Smith T Lewis-Jos Magnetic , Smith T, Lewis-Jones H, Leijon G. Magnetic resonance pathology of central post stroke pain (CPSP). Proc XIth Int Congr
Neuropathol 1990; 384.
9 Lewis-Jones H, Smith T, Bowsher D, Leijon G. Magnetic resonance imaging in 36 cases of central post-stroke pain (CPSP). Pain 1990 suppl. 5: S278.

10 Davison C, Schick W. Spontaneous pain and other sensory disturbances. Arch Neurol Psychiat (Chicago) 1935; 34: 1204-37.

11 Bowsher DR Foy PM, Shaw MDM. Central pain pain com morrhage. $\mathrm{Br} \mathcal{F}$ Neurosur 1989; 3: 435-43. 
12 Garcin R. La douleur dans les affections organiques du système nerveux central. Rev Neurol

13 Bowsher D. Termination of the central pain pathway in man: the conscious appreciation of pain. Brain 1957; 80: 606-22.

14 Jones AKP, Friston KJ, Brown D, Qi L, Frackowiak RSJ. Cortical and subcortical localisation of response to pain in man usin positron emission tomography. Proc $R$ Soc Lond $B$ 1991; 244: 39-44.

15 Lahuerta J, Bowsher D, Buxton PH, Lipton S. Percutaneous cervical cordotomy: A review of Percuraneous cervical cordotomy. A review of 181 operations in 146 patients, including a study on the location of 'pain fibers' in the second cervical spinal cord segment of 29 cases. $f$ Neurosurg 1994; 80: 975-85.

16 Bowsher D. Cerebrovascular disease: sensory consequences of stroke. Lancet 1993; 341: 156.

17 Bond MR, Pilowsky I. The subjective assessment of pain and its relationship to the administration of analgesics in patients with advanced cancer. F Psychosom Res 1966; 10: 203-7.

18 Bowsher, D. Neurogenic pain syndromes and their management. Br Med Bull 1991; 47: 644-6.

19 Leijon G, Boivie J. Central post-stroke pain -a controlled trial of amitriptyline and carbamazepine. Pain 1989; 36: 27-36.

20 Bainton T, Fox M, Bowsher D, Wells C. A double-blind trial of naloxone in central poststroke pain. Pain 1992; 48: 159-162.
21 Loh L, Nathan PW, Schott GD.Pain due to lesions of the central nervous system removed by

22 Koppel BS. Amitriptyline in the treatment of thalamic pain. Southern Med $f$ 1982; 79: 759-61.

23 Leijon G, Boivie J. Pharmacological treatment of central pain. In: Casey KL, ed. Pain and central nervous system disease: the central pain syndromes New York: Raven Press, 1991; pp 257-66.

24 Ardid D, Guilbaud G. Antinociceptive effects of acute and 'chronic' injections of tricyclic antidepressant drugs in a new model of mo

R $R$. Efficacy of antidepressants in relieving diabetic neuropathy pain: amitriptyline vs desipramine, and fluoxetine vs placebo. Neurology 1990; 40 (suppl 1): 437

26 Max MB, Schafer SC, Culnane M, Smoller B, Dubner R, Gracely RH. Amitriptyline, but not lorazepam, relieves postherpetic neuralgia. Neurology 1988; 38: 1427-32.

27 Watson CP, Evans RJ. A comparative trial of amitriptyline and zimelidine in postherpetic neuralgia. Pain 1985; 23: 357-60.

28 Watson CP, Evans RJ, Reed K, Merskey $H$ Goldsmith Warsh J. Amitriptyline versus Goldsmith L, Warsh J. Amitriptyline versus placebo in postherpetic neuralgia. Neurology
1982; 32: $671-3$.
29 Bowsher D, Nurmikko T, Leijon G. Essential sensory deficit for the development of sensory deficit for the development of neurogenic pain following herpes zoster and
stroke. 7th World Congr Pain, 1993 Abstracts, stroke. 7th World Congr Pain, 1993 Abstracts, p 409

30 Bhala BB, Ramamoorthy C, Bowsher D, Yelnoorker KN. Shingles and post-herpetic neuralgia. Clin f Pain 1988; 4: 169-74.

31 Nurmikko T, Wells C, Bowsher D. Pain and allodynia in postherpetic neuralgia: role of somatic and sympathetic systems. Acta Neurol Scand 1991; 84: 146-52.

32 Todd AJ, McKenzie J GABA-immunoreactive neurons in the dorsal horn of the rat spinal cord. Neuroscience 1989; 31: 799-806. spinal cord.

rbuch GI, Sandyk R. Mexiletine for . ${ }^{2}$ Neurosci 1990; 55: 129-33.

34 Tsubokawa $T$, Katayama $Y$, Yamamoto $T$, Hirayama T, Koyama S. Chronic motor corte stimulation in patients with thalamic pain. Neurosurg 1993; 78: 393-401.

35 Chapman CE, Bushnell MC, Miron D, Duncan GH, Lund JP. Sensory perception durin movement in man. Exp Brain Res 1987; 68: 516-24.

36 Milne RJ, Aniss AM, Kay NE, Gandevia SC Reduction in perceived intensity of cutaneous stimuli during movement -a quantitative study Exp Brain Res 1988; 70: 569-76.

\section{Medical Anniversary \\ HAMILTON BAILEY, 1 OCTOBER 1894}

Hamilton Bailey (1894-1961) was born at Bishopstoke, Hampshire, UK, son of a Christian medical missionary. He was a medical student at the London Hospital, qualified in 1916, and then joined the Royal Navy. He was surgeon to the Royal Northern Hospital (1930-50), where he and RJ McNeill Love produced their Short practice of surgery and many other successful books. He died on $26 \mathrm{March}$ 1961 in Malaga, Spain, following surgery for a carcinoma of the colon. - D Geraint fames

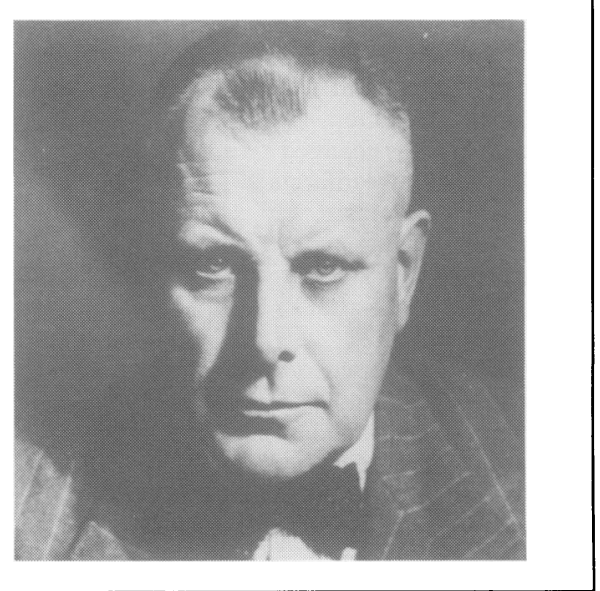

